\title{
molecules
}

ISSN 1420-3049

www.mdpi.com/journal/molecules

Article

\section{$E$ - and $Z$-Isomers of New Phytoecdysteroid Conjugates from French Polynesian Microsorum membranifolium (Polypodiaceae) Fronds}

\author{
Raimana Ho ${ }^{1}$, Jean-Pierre Girault ${ }^{2}$, Phila Raharivelomanana ${ }^{1, *}$ and René Lafont ${ }^{3}$ \\ 1 Laboratoire Biodiversité Terrestre et Marine, Université de la Polynésie Française, \\ B.P. 6570 Faa'a, 98702 FAA'A, Tahiti, French Polynesia \\ 2 Laboratoire de Chimie et Biochimie Pharmacologiques et Toxicologiques, CNRS UMR 8601, \\ Université Paris Descartes, 45 rue des Saints Pères, 75270 Paris, Cedex 06, France \\ 3 Laboratoire BIOSIPE, ER3, Paris 6 - Pierre et Marie Curie, Case 29, 7 Quai Saint Bernard, \\ 75252 Paris, Cedex 5, France
}

* Author to whom correspondence should be addressed; E-Mail: phila.raharivelomanana@upf.pf; Tel.: +689-803-803; Fax: +689-803-804.

Received: 29 August 2012; in revised form: 21 September 2012 / Accepted: 24 September 2012 / Published: 28 September 2012

\begin{abstract}
Phytochemical investigation of the fronds of Microsorum membranifolium resulted in the isolation of a new phytoecdysteroid, E-2-deoxy-20-hydroxyecdysone 3-[4(1- $\beta$-D-glucopyranosyl)]-caffeate (1), together with two known phytoecdysteroids, $E$-2deoxy-20-hydroxyecdysone 3-[4-(1- $\beta$-D-glucopyranosyl)]-ferulate (2), E-2-deoxyecdysone 3-[4-(1- $\beta$-D-glucopyranosyl)]-ferulate (3). Their respective $Z$-isomers 4-6 were also observed and identified for the first time. The new structures were elucidated on the basis of extensive spectroscopic data analysis (1D, 2D-NMR and HR-MS techniques).
\end{abstract}

Keywords: phytoecdysteroids; fronds; Microsorum membranifolium (R. Br.) Ching; Polypodiaceae; French Polynesia

\section{Introduction}

Microsorum membranifolium, which belongs to the Polypodiaceae family, is one of the most frequently used fern species in Polynesian traditional medicine. The fronds and/or the rhizomes of M. membranifolium, named "Metuapua'a" in French Polynesia, are usually prescribed in popular 
remedies to treat stomach ache, gonorrhoea, pneumonia, leucorrhoea, sterility, dislocations and fractures [1-3]. This plant contains phytoecdysteroids as main bioactive components, including ecdysone, 20-hydroxyecdysone, 2-deoxy-20-hydroxyecdysone and 2-deoxyecdysone [4]. Previous phytochemical investigation of the fronds of the medicinal fern M. membranifolium revealed a new class of phytoecdysteroid conjugates [5]. As a part of a continuing project to study this new class of phytoecdysteroid conjugates, we investigated the $\mathrm{BuOH}$ fraction of the fronds of this medicinal fern. A new phytoecdysteroid, E-2-deoxy-20-hydroxyecdysone 3-[4-(1- $\beta$-D-glucopyranosyl)]-caffeate (1), together with two known phytoecdysteroids, E-2-deoxy-20-hydroxyecdysone 3-[4-(1- $\beta$-Dglucopyranosyl)]-ferulate (2), E-2-deoxyecdysone 3-[4-(1- $\beta$-D-glucopyranosyl)]-ferulate (3), and their respective $Z$-isomers 4-6 were also observed and identified for the first time. In this paper, we present the isolation and structural determination of these phytoecdysteroids (1-6, Figure 1) from Microsorum membranifolium (R. Br.) Ching.

Figure 1. Chemical structures of phytoecdysteroids 1-6 from M. membranifolium.
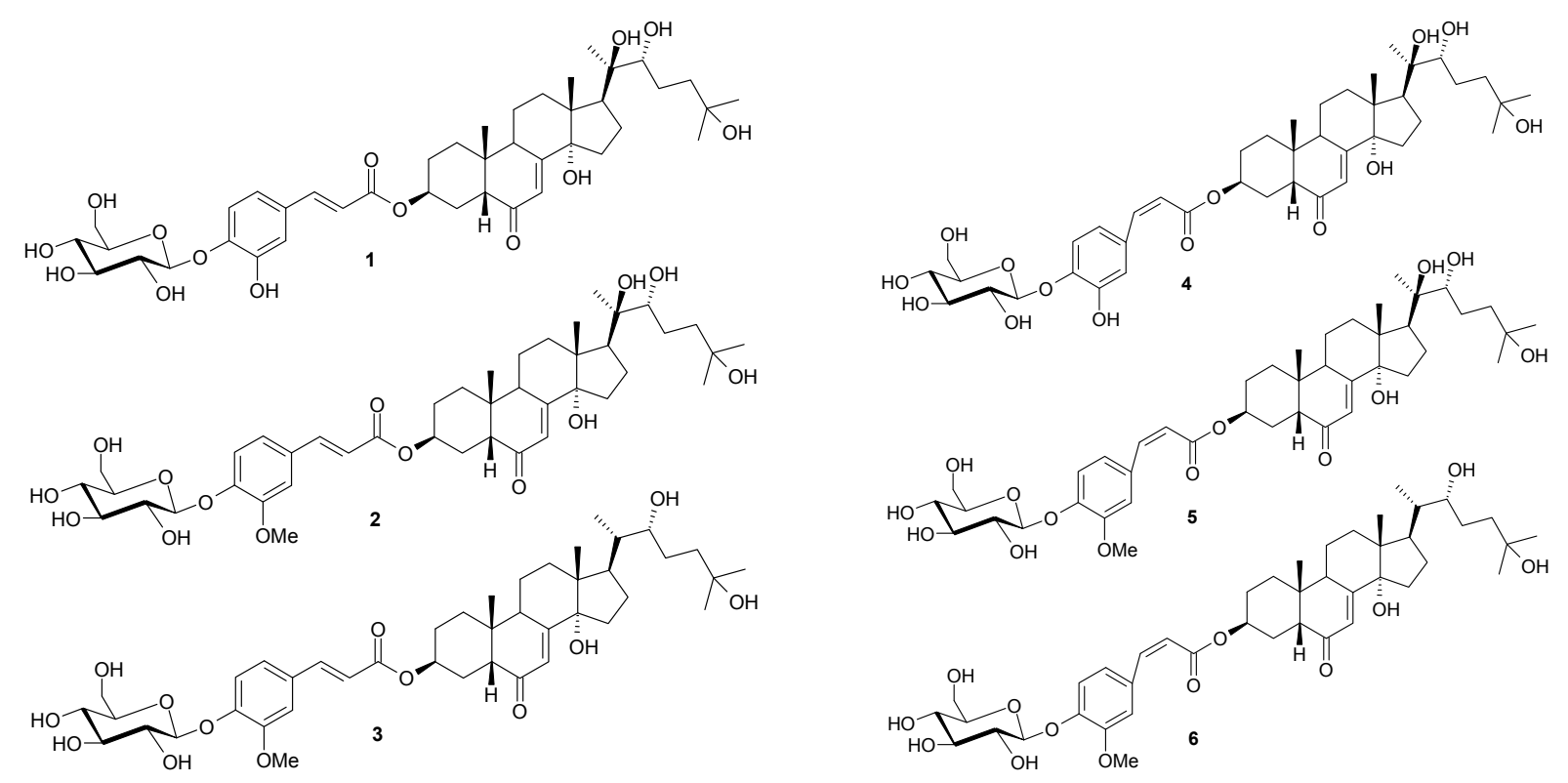

\section{Results and Discussion}

The chemical investigation of the butanolic extract of the fronds of Microsorum membranifolium led to the isolation of the new compound E-2-deoxy-20-hydroxyecdysone 3-[4-(1- $\beta$-D-glucopyranosyl)]-caffeate (1), along with two known phytoecdysteroids $\mathbf{2}$ and $\mathbf{3}$ and their respective cis isomers 4, 5 and $\mathbf{6}$.

Compound 1 was obtained as a white amorphous powder. The mass spectrum was consistent with a M.W. of $788 \mathrm{amu}$. The UV spectrum shows a typical ecdysteroid spectrum, with a maximum at $240 \mathrm{~nm}$ (in EtOH), but in addition to the major absorbance at $240 \mathrm{~nm}$, peaks were observed at 290 and $313 \mathrm{~nm}$, which are indicative of the presence of an aromatic conjugating moiety. Initial examination of the ${ }^{1} \mathrm{H}-\mathrm{NMR}$ spectrum of this compound shows that it presents an ecdysteroid aglycone conjugated with a glycoside sugar. The presence of a sugar is straightforward, since one observes additional peaks in the region of hydrogen bound to oxygenated carbons (3.2-4.95 ppm) and the corresponding carbon signals (60-105 ppm) in the ${ }^{13} \mathrm{C}-\mathrm{NMR}$ spectrum. On the other hand, we could note the presence of a slightly 
different aromatic moiety, but with a relatively similar spin system with respect to ferulate compounds 2 and 3 [5]. However, this aromatic group presents the loss of the methyl signal of the methoxy group present in ferulate [4,5]. This could be consistent with a caffeate structure for this aromatic moiety. The NMR spectroscopic evidence below confirmed this assignment. Inspection of the ${ }^{1} \mathrm{H}-\mathrm{NMR}$ of the ecdysteroid core of this molecule shows five singlet methyl signals for compound $\mathbf{1}$. This is typical of 20-hydroxy-derivatives, which was also confirmed after assignment of ${ }^{1} \mathrm{H}$ or ${ }^{13} \mathrm{C}$ signals by means of $1 \mathrm{D}$ and $2 \mathrm{D}$ experiments. Moreover this compound does not show significant changes in its ${ }^{1} \mathrm{H}$ or ${ }^{13} \mathrm{C}$ chemical shifts for the signals of the side-chain or of rings $\mathrm{B}, \mathrm{C}$ and $\mathrm{D}$ of the ecdysteroid core. However, as for the A-ring of 2-deoxy-20-hydroxy-ecdysone 3-[4-(1- $\beta$-D-glucopyranosyl)]-ferulate (2), we observe the typical features of 2-deoxy compounds (lack of $\mathrm{H}-2$ in the $>\mathrm{CHOH}$ zone, broadening of $\mathrm{H}_{\mathrm{eq}}-3$ and of 3-esterified derivatives $\left(\mathrm{H}_{\mathrm{eq}}-3: \delta=5.11 \mathrm{ppm}\right.$, broad singlet, $\left.\mathrm{w}_{1 / 2}=13 \mathrm{~Hz}\right)[6,7]$. Finally, examination of the ${ }^{1} \mathrm{H}$ and ${ }^{13} \mathrm{C}$ spectral data of the conjugated moieties led to the identification of the aromatic moiety as a caffeate and for the sugar moiety as a $\beta$-D glucoside as follows [8]: (i) the sugar presents one oxymethylene and five oxymethine groups in agreement with a hexose sugar; this hexose presents a ${ }^{1} \mathrm{H}$ anomeric NMR signal $\mathrm{H}-1$ ' at $\delta=4.86 \mathrm{ppm}$ in agreement with a 1 '-glycosidic link to the rest of the molecule. On the other hand, the large ${ }^{3} J$ coupling (doublet, $7.3 \mathrm{~Hz}$ ) is in accordance with a $\mathrm{H}_{\text {axial }}-\mathrm{H}_{\text {axial }}$ coupling constant and consequently with an axial position of both $\mathrm{H}-\mathrm{1}^{\prime}$ and $\mathrm{H}-\mathrm{2}^{\prime}$ protons. ${ }^{1} \mathrm{H}$ selective homonuclear decoupling experiments for H-1', H-6' and H-6" and examination of 2D TOCSY cross-peaks show clearly that H-3', H-4' and $\mathrm{H}-5^{\prime}$ are in axial positions owing to the large ${ }^{3} J$ coupling constants of H-2'-H-3', H-3'-H-4' and H-4'-H-5'. 2D ROESY experiments present ROE correlations in agreement with this conclusion, so we conclude that sugar moiety is a $\beta$-D glucoside; (ii) the linkage of this $\beta$-D glucoside was deduced from 2D HMBC experiments as one observes a correlation from $\mathrm{H}-1$ ' to a quaternary carbon of the aromatic part of the molecule. This shows that the glucoside is linked with the aromatic moiety, which is itself linked to the ecdysteroid core moiety by an ester bond. This is confirmed from a ROE correlation observed for H-5 ( $\delta=2.38 \mathrm{ppm})$ with H- 8 " ( $\delta=6.40 \mathrm{ppm}$ ). No correlation could be observed from 2D HMBC experiment for the broad H-3, as this signal has unfavorable relaxation properties; (iii) the aromatic moiety presents ${ }^{1} \mathrm{H}$ and ${ }^{13} \mathrm{C}$ spectral data of an ester group linked to a double bond bearing two ethylenic protons in trans-configuration (unambiguously established from the value of their large $[16.1 \mathrm{~Hz}]^{3} J$ coupling constant).

Again, from 2D HMBC experiments, this double bond could be linked to a phenyl ring bearing three protons, a hydroxy group and the glucosidic link with the sugar (see above). The aromatic proton at $\delta=7.14 \mathrm{ppm}(\mathrm{d}, J=1.8)$ presents ROE correlations with the two ethylenic protons $\mathrm{H}-7$ " and $\mathrm{H}-8$ " (Figure 2). All these elements together with MS data are in agreement with a caffeate structure for this aromatic group. In conclusion, compound 1 corresponds to $E$-2-deoxy-20-hydroxyecdysone 3-[4-(1- $\beta$ D-glucopyranosyl)]-caffeate.

Figure 2. Selected ROE correlations of compound 1.

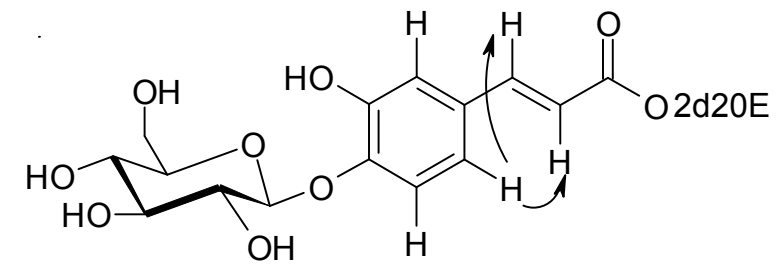


The two other known compounds were identified as $E$-2-deoxy-20-hydroxyecdysone 3-[4-(1- $\beta$-Dglucopyranosyl)]-ferulate (2) [5] and E-2-deoxyecdysone 3-[4-(1- $\beta$-D-glucopyranosyl)]-ferulate (3) [5], by interpretation of their spectroscopic data.

In NMR spectra of compounds 1, 2 and 3, we could note the presence of signals of other compounds (4, 5 and 6) very similar to compounds 1, 2 and 3 (with ratio of ca 20\% after initial dissolution in $\mathrm{CD}_{3} \mathrm{OD}$ and $55 \%$ after 1 month), but which only present main differences in the signals of the ferulate moiety for $\mathbf{2}$ and $\mathbf{3}$ and of the caffeate moiety for $\mathbf{1}$. These added signals correspond to the presence of ethylenic double bound cis (Z)-isomer compounds of ferulate and cafeate in mixtures with compounds $\mathbf{1}, \mathbf{2}$ and $\mathbf{3}$, which have a trans $(E)$-configuration of the ethylenic double bond. This cis-configuration led to a significant variation of chemical shift of the ethylenic proton signals $\mathrm{H}-7$ " and H-8". The value of $12.8 \mathrm{~Hz}$ for ethylenic coupling constants ${ }^{3} \mathrm{~J} \mathrm{H}-7$ "-H-8" is in agreement with this cis-configuration. We could note that for their respective trans-isomers, a value of $16.1 \mathrm{~Hz}$ is observed for their ${ }^{3} J$ H-7"-H-8" coupling constants in agreement with their trans (E)-configuration of their double bond. Moreover the cis configuration of these compounds is confirmed thanks to the large NOE effect observed between ${ }^{1} \mathrm{H}$ signal of $\mathrm{H}-7$ " and $\mathrm{H}-8$ ". Ferulate and caffeate compounds belong to the family of cinnamic compounds derivatives for which thermodynamic equilibrium of cis-isomer with its trans-isomer is a well-known phenomenon $[9,10]$. Although the trans-cis-equilibrium is common, this is the first time that the cis-isomers 4-6 in this new class of ecdysteroid conjugates (glycosyl-ferulates and -caffeates) have been observed and identified.

Three analytical high performance liquid chromatography (HPLC) methods have been developed for the separation of isomers of these phytoecdysteroids. We observed that the elution order of the $Z$-isomers was reversed in comparison with the $E$-isomers between the two normal-phase HPLC systems (System B and C). We also noted that the isomers eluted in the same order with the systems A (RP) and B (NP). With the system C, compound $\mathbf{2}$ eluted surprisingly much later than compound $\mathbf{1}$. This result was unexpected as compound $\mathbf{1}$ should be more polar than $\mathbf{2}$ because of its free hydroxy instead of a methoxy group. Chromatographic data are reported in Table 1.

Table 1. HPLC data for the different phytoecdysteroids.

\begin{tabular}{cccc}
\hline \multirow{2}{*}{ Phytoecdysteroid } & \multicolumn{3}{c}{ Retention time (min) } \\
\cline { 2 - 4 } & System A & System B & System C \\
\hline $\mathbf{1}$ & 25.7 & 15.9 & 15.6 \\
$\mathbf{2}$ & 26.7 & 12.3 & 17.6 \\
$\mathbf{3}$ & 34.0 & 9.2 & 14.2 \\
$\mathbf{4}$ & 32.0 & 25.2 & 13.5 \\
$\mathbf{5}$ & 33.5 & 19.2 & 16.0 \\
$\mathbf{6}$ & 41.0 & 12.7 & 12.7 \\
20-hydroxyecdysone & 7.5 & 16.0 & 9.4 \\
2-deoxy-20-hydroxyecdysone & 15.4 & 8.3 & 6.0 \\
2-deoxyecdysone & 24.1 & 6.1 & 5.0 \\
\hline
\end{tabular}




\section{Experimental}

\subsection{General}

UV spectra were recorded in EtOH with a Varian DMS 100 spectrometer. The NMR spectra were obtained on a Bruker Avance 500 (Wissembourg, France) at $300 \mathrm{~K}$. The samples were lyophilized in $\mathrm{D}_{2} \mathrm{O}$ and dissolved in $\mathrm{CD}_{3} \mathrm{OD} .{ }^{1} \mathrm{H}$ signal of residual $\mathrm{CHD}_{2} \mathrm{OD}(3.31 \mathrm{ppm})$ and of ${ }^{13} \mathrm{C}$ signal of

${ }^{13} \mathrm{CD}_{3} \mathrm{OD}$ (49.0 ppm) were used as internal reference respectively for proton and carbon shifts $(\delta \pm 0.2 \mathrm{ppm})$. Chemical shifts are expressed in ppm. 1D ${ }^{1} \mathrm{H}$ and ${ }^{13} \mathrm{C}$ spectra and 2D COSY, TOCSY, NOESY, ROESY, PFG-HSQC and PFG-HMBC NMR spectra further allowed the ${ }^{1} \mathrm{H}$ and ${ }^{13} \mathrm{C}$ assignments [6,11]. ESIMS were recorded on a Jeol JMS-700 spectrometer (Croissy sur Seine, France) either in desorption/chemical ionization (CI/D) mode or fast-atom bombardment (FAB) mode. HRESIMS data were obtained on a LTQ-Orbitrap-XL mass spectrometer. HPLC-UV-DAD analysis was carried out on a HP 1100 system equipped with a photodiode array detector (Agilent Technology, Palo Alto, CA, USA) with an Interchrom $\mathrm{C}_{18}$ column $(250 \times 4.6 \mathrm{~mm})$. Preparative HPLC separation (HP 1100) was carried out on a Chromanorm $\mathrm{C}_{18}$ S5 ODS II $(250 \times 20 \mathrm{~mm})$ and a Zorbax-SIL $(250 \times 4.6 \mathrm{~mm})$ with a photodiode array detector. Polyamide DC $6(50-160 \mathrm{~mm}$, Fluka) was used for column chromatography. Thin-layer chromatography was performed on silica gel $60 \mathrm{~F}_{254} \mathrm{~A} 1$ sheets (Merck, Darmstadt, Germany) and spots were visualized under UV (254 nm).

\subsection{Plant Material}

Fronds of Microsorum membranifolium (R. Br.) Ching were collected in Tahiti (French Polynesia) in the district of Papenoo in May 2007 and were identified by Dr. Jacques Florence. A voucher specimen has been deposited at the Herbarium of the "Museum of Tahiti and its Islands" in Punaauia (PAP, Tahiti Island).

\subsection{Extraction and Isolation}

The dried, milled fronds of M. membranifolium $(1.15 \mathrm{~kg})$ were exhaustively extracted with ethanol (4 L) with continuous stirring over 2 days at room temperature. The extract was filtered and the filtrate evaporated under reduced pressure to yield a syrup-like residue $(33.81 \mathrm{~g})$. The syrup was partitioned between $\mathrm{CHCl}_{3}, \mathrm{H}_{2} \mathrm{O}$ and then $n$ - $\mathrm{BuOH}$ to give $4.14 \mathrm{~g}, 20.93 \mathrm{~g}$ and $8.83 \mathrm{~g}$ portions, respectively. The $\mathrm{BuOH}$ fraction was chromatographed using a column of polyamide and elution with $25 \% \mathrm{EtOH}-\mathrm{H}_{2} \mathrm{O}$ yielded 10 fractions. Similar fractions were combined after TLC and HPLC examination to provide four fractions, A (1.28 g), B (0.6 g), C (2.25 g) and D (4.62 g). Fraction B was submitted to a preparative chromatography using $\mathrm{C}_{18}$ column and a stepwise mobile phase gradient of $\mathrm{ACN} / \mathrm{water}$ to afford twelve sub-fractions B1-B12. Compounds $1\left(1.5 \mathrm{mg}, \mathrm{t}_{\mathrm{R}}=23.9 \mathrm{~min}\right)$ and $4\left(1.2 \mathrm{mg}, \mathrm{t}_{\mathrm{R}}=22.4 \mathrm{~min}\right)$ were obtained by preparative normal-phase HPLC (Zorbax-SIL, $250 \times 4.6$ i.d.) of the sub-fraction B4 (2.7 mg; eluted with cyclohexane/isopropanol/water 100:50:3). Sub-fraction B6 (13.5 mg) eluted with dichloromethane/isopropanol/water (125:40:3) was separated on Zorbax-SIL, to afford 2 (4 mg, $\left.\mathrm{t}_{\mathrm{R}}=10.8 \mathrm{~min}\right)$ and $\mathbf{5}\left(3 \mathrm{mg}, \mathrm{t}_{\mathrm{R}}=12.3 \mathrm{~min}\right)$. In addition, sub-fraction $\mathrm{B} 10(8.5 \mathrm{mg})$ was purified by normal 
preparative HPLC with dichloromethane/isopropanol/water $(125: 40: 3)$ to give $\mathbf{3}\left(3 \mathrm{mg}, \mathrm{t}_{\mathrm{R}}=8.8 \mathrm{~min}\right)$ and $\mathbf{6}\left(2 \mathrm{mg}, \mathrm{t}_{\mathrm{R}}: 9.4 \mathrm{~min}\right)$.

\subsection{Analytical HPLC Methods}

HPLC equipment from Thermo was used for checking the separation of the isomers. Analytical

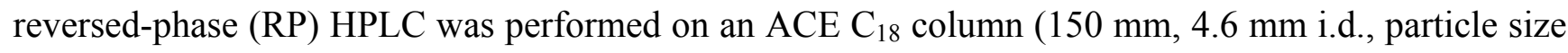
$5 \mu \mathrm{m}$, from A.I.T.), eluted at a flow-rate of $1 \mathrm{~mL} / \mathrm{min}$ with a linear gradient (15\% to $35 \%$ acetonitrileisopropanol $[5: 2 \mathrm{v} / \mathrm{v}]$ in water containing $0.1 \%$ trifluoroacetic acid in $40 \mathrm{~min}$, then $35 \%$ to $100 \%$ in $30 \mathrm{~min}$ ) (System A). Analytical normal-phase (NP) HPLC used an ACE 5 SIL column (150 mm, $4.6 \mathrm{~mm}$ i.d., particle size $5 \mu \mathrm{m}$, from A.I.T.), eluted at a flow-rate of $1 \mathrm{~mL} / \mathrm{min}$ with dichloromethane-isopropanolwater (125:30:2, v/v/v) (System B) or with cyclohexane-isopropanol-water (100/40/3, v/v/v) (System C).

E-2-Deoxy-20-hydroxyecdysone 3-[4-(1- $\beta$-D-glucopyranosyl)]-caffeate (1): white amorphous powder; UV (EtOH) $\lambda_{\max }(\log \varepsilon) \mathrm{nm}: 242,290,313$; HRESIMS (positive ion mode) $m / z: 811.38726$ [M+Na] $]^{+}$, (calc. for $\mathrm{C}_{42} \mathrm{H}_{60} \mathrm{O}_{14} \mathrm{Na}, 811.38753$ ); ${ }^{1} \mathrm{H}-\mathrm{NMR}$ and ${ }^{13} \mathrm{C}-\mathrm{NMR}$ data are shown in Tables 2 and 3.

E-2-Deoxy-20-hydroxyecdysone 3-[4-(1- $\beta$-D-glucopyranosyl)]-ferulate (2): white amorphous powder; UV (EtOH) $\lambda_{\max }(\log \varepsilon) \mathrm{nm}: 240,294,317$; ESIMS (+) $\mathrm{m} / z 825[\mathrm{M}+\mathrm{Na}]^{+}, 841[\mathrm{M}+\mathrm{K}]^{+}$; HRESIMS (positive ion mode) $\mathrm{m} / \mathrm{z}$ : $825.40282[\mathrm{M}+\mathrm{Na}]^{+}$, (calc. for $\mathrm{C}_{43} \mathrm{H}_{62} \mathrm{O}_{14} \mathrm{Na}, 825.40318$ ); ${ }^{1} \mathrm{H}-\mathrm{NMR}$ and ${ }^{13} \mathrm{C}-\mathrm{NMR}$ data are shown in Tables 2 and 3.

E-2-Deoxyecdysone 3-[4-(1- $\beta$-D-glucopyranosyl)]-ferulate (3): white amorphous powder; UV (EtOH) $\lambda_{\max }(\log \varepsilon) \mathrm{nm}: 240,294,317$; ESIMS $(+) \mathrm{m} / z 825[\mathrm{M}+\mathrm{K}]^{+}, 809[\mathrm{M}+\mathrm{Na}]^{+}, 787[\mathrm{M}+\mathrm{H}]^{+} ;{ }^{1} \mathrm{H}-\mathrm{NMR}$ and ${ }^{13} \mathrm{C}-\mathrm{NMR}$ data are shown in Tables 2 and 3.

Table 2. ${ }^{1} \mathrm{H}-\mathrm{NMR}$ data for compounds $\mathbf{1}-\mathbf{6}$ in $\mathrm{CD}_{3} \mathrm{OD}(\delta$ in ppm, $J$ in $\mathrm{Hz})$.

\begin{tabular}{|c|c|c|c|c|c|c|}
\hline & $\delta_{H}(\mathbf{1})$ & $\delta_{H}(2)$ & $\delta_{H}(3)$ & $\delta_{H}(4)$ & $\delta_{H}(5)$ & $\delta_{\mathrm{H}}(\mathbf{6})$ \\
\hline Hax -1 & & 1.46 & 1.46 & & & \\
\hline Heq-1 & & 1.76 & 1.76 & & & \\
\hline Hax-2 & & 1.87 & 1.87 & & 1.77 & \\
\hline Heq-2 & & 1.94 & 1.94 & & & \\
\hline Heq-3 & $\begin{array}{l}5.16(\mathrm{~s}, \mathrm{br}, \\
\left.\mathrm{w}_{1 / 2}=13\right)\end{array}$ & $\begin{array}{l}5.18(\mathrm{~s}, \mathrm{br} \\
\left.\mathrm{w}_{1 / 2}=13\right)\end{array}$ & $\begin{array}{l}5.16(\mathrm{~s}, \mathrm{br} \\
\left.\mathrm{w}_{1 / 2}=14\right)\end{array}$ & $\begin{array}{l}5.12(\mathrm{~s}, \mathrm{br} \\
\left.\mathrm{w}_{1 / 2}=13\right)\end{array}$ & $\begin{array}{l}5.11(\mathrm{~s}, \mathrm{br}, \\
\left.\mathrm{w}_{1 / 2}=13\right)\end{array}$ & $\begin{array}{l}5.11(\mathrm{~s}, \mathrm{br}, \\
\left.\mathrm{w}_{1 / 2}=13\right)\end{array}$ \\
\hline Hax-4 & 1.77 & 1.77 & 1.77 & & 1.77 & \\
\hline Heq-4 & 1.87 & 1.87 & 1.87 & & 1.87 & \\
\hline $\mathrm{H}-5$ & $\begin{array}{c}2.38(\mathrm{~d}, \mathrm{~d} \\
12.3,4.0)\end{array}$ & $\begin{array}{c}2.40(\mathrm{~d}, \mathrm{~d}, 12.3 \\
4.0)\end{array}$ & $\begin{array}{c}2.41(\mathrm{~d}, \mathrm{~d}, 12.6 \\
4.2)\end{array}$ & 2.15 & 2.2 & 2.2 \\
\hline $\mathrm{H}-7$ & $5.84(\mathrm{~d}, 2.1)$ & $5.84(\mathrm{~d}, 2.4)$ & $5.85(\mathrm{~d}, 2.0)$ & $5.80(\mathrm{~d}, 2.1)$ & $5.81(\mathrm{~d}, 2.1)$ & $5.81(\mathrm{~d}, 2.1)$ \\
\hline Hax-9 & 3.28 & 3.27 & $3.27\left(\mathrm{~m}, \mathrm{w}_{1 / 2}=26\right)$ & 3.21 & 3.23 & 3.21 \\
\hline Hax-11 & 1.68 & 1.68 & 1.67 & & 1.63 & 1.67 \\
\hline Heq-11 & 1.76 & 1.76 & 1.78 & & 1.71 & 1.78 \\
\hline Hax-12 & 2.15 & $\begin{array}{c}2.15(\mathrm{t}, \mathrm{d}, 13.0 \\
4.8)\end{array}$ & $\begin{array}{c}2.13(\mathrm{t}, \mathrm{d}, 13.0 \\
4.8)\end{array}$ & 2.13 & 2.13 & \\
\hline Heq-12 & 1.86 & 1.88 & 1.78 & & 1.87 & \\
\hline
\end{tabular}


Table 2. Cont.

\begin{tabular}{|c|c|c|c|c|c|c|}
\hline & $\delta_{\mathrm{H}}(\mathbf{1})$ & $\delta_{H}(2)$ & $\delta_{\mathrm{H}}(3)$ & $\delta_{H}(4)$ & $\delta_{H}(5)$ & $\delta_{H}(6)$ \\
\hline Hax-15 & 2.00 & 2.00 & 1.98 & & 2.00 & 1.98 \\
\hline Heq-15 & 1.63 & 1.63 & 1.62 & & 1.63 & 1.62 \\
\hline Hax-16 & 2.00 & 2.00 & 1.98 & 2.00 & 2.00 & 1.98 \\
\hline Heq-16 & 1.76 & 1.76 & 1.51 & 1.76 & 1.76 & 1.51 \\
\hline $\mathrm{H}-17$ & $2.42(t, 9.9)$ & $2.42(t, 9.9)$ & 2.06 & 2.42 & 2.42 & 2.06 \\
\hline $\mathrm{Me}-18$ & $0.908(\mathrm{~s})$ & $0.907(\mathrm{~s})$ & $0.745(\mathrm{~s})$ & $0.880(\mathrm{~s})$ & $0.890(\mathrm{~s})$ & $0.735(\mathrm{~s})$ \\
\hline Me-19 & $1.010(\mathrm{~s})$ & $1.010(\mathrm{~s})$ & $1.010(\mathrm{~s})$ & $0.890(\mathrm{~s})$ & $0.910(\mathrm{~s})$ & $0.910(\mathrm{~s})$ \\
\hline $\mathrm{H}-20$ & & & 1.77 & & & 1.77 \\
\hline Me-21 & $1.203(\mathrm{~s})$ & $1.203(\mathrm{~s})$ & $0.957(\mathrm{~d}, 6.6)$ & $1.203(\mathrm{~s})$ & $1.203(\mathrm{~s})$ & $0.950(\mathrm{~d}, 6.6)$ \\
\hline $\mathrm{H}-22$ & 3.36 & 3.35 & $3.61(\mathrm{~d}, \mathrm{br}, 10.1)$ & 3.36 & 3.35 & 3.61 \\
\hline На-23 & 1.31 & 1.31 & 1.33 & 1.31 & 1.31 & 1.33 \\
\hline $\mathrm{Hb}-23$ & 1.69 & 1.69 & 1.55 & 1.69 & 1.69 & 1.55 \\
\hline На-24 & 1.81 & 1.81 & 1.79 & 1.81 & 1.81 & 1.79 \\
\hline $\mathrm{Hb}-24$ & 1.44 & 1.46 & 1.42 & 1.44 & 1.46 & 1.42 \\
\hline Me-26 & $1.197(\mathrm{~s})$ & $1.197(\mathrm{~s})$ & $1.200(\mathrm{~s})$ & $1.197(\mathrm{~s})$ & $1.197(\mathrm{~s})$ & $1.195(\mathrm{~s})$ \\
\hline Me-27 & $1.211(\mathrm{~s})$ & $1.211(\mathrm{~s})$ & $1.210(\mathrm{~s})$ & $1.211(\mathrm{~s})$ & $1.211(\mathrm{~s})$ & $1.205(\mathrm{~s})$ \\
\hline $\mathrm{H}-1^{\prime}$ & $4.86(\mathrm{~d}, 7.3)$ & $4.98(\mathrm{~d}, 7.3)$ & $4.98(\mathrm{~d}, 7.3)$ & $4.82(\mathrm{~d}, 7.3)$ & $4.96(\mathrm{~d}, 7.3)$ & $4.96(\mathrm{~d}, 7.3)$ \\
\hline $\mathrm{H}-2^{\prime}$ & 3.53 & $3.53(\mathrm{~d}, \mathrm{~d}, 9.0,7.5)$ & $3.53(\mathrm{~d}, \mathrm{~d}, 9.0,7.5)$ & & 3.48 & 3.53 \\
\hline $\mathrm{H}-3^{\prime}$ & 3.48 & $3.48(\mathrm{t}, 9.0)$ & $3.48(\mathrm{t}, 9.0)$ & & & 3.48 \\
\hline H-4' & 3.42 & $3.43(\mathrm{~d}, \mathrm{~d}, 9.5,8.6)$ & $3.43(\mathrm{~d}, \mathrm{~d}, 9.5,8.6)$ & & & 3.43 \\
\hline H-5' & 3.46 & $\begin{array}{c}3.45(\mathrm{~d}, \mathrm{~d}, \mathrm{~d}, 9.5 \\
5.2,2.2)\end{array}$ & $\begin{array}{c}3.45(\mathrm{~d}, \mathrm{~d}, \mathrm{~d}, 9.5 \\
5.2,2.2)\end{array}$ & 3.46 & & 3.44 \\
\hline H-6 & $\begin{array}{l}3.72(\mathrm{~d}, \mathrm{~d} \\
12.5,5.3)\end{array}$ & $\begin{array}{c}3.70(\mathrm{~d}, \mathrm{~d}, 12.0 \\
5.0)\end{array}$ & $\begin{array}{c}3.70(\mathrm{~d}, \mathrm{~d}, 12.0 \\
5.0)\end{array}$ & $\begin{array}{l}3.72(\mathrm{~d}, \mathrm{~d} \\
12.5,5.3)\end{array}$ & $\begin{array}{c}3.70(\mathrm{~d}, \mathrm{~d}, 12.0 \\
5.0)\end{array}$ & $\begin{array}{l}3.70(\mathrm{~d}, \mathrm{~d} \\
12.0,5.0)\end{array}$ \\
\hline H-6 & $\begin{array}{l}3.91(\mathrm{~d}, \mathrm{~d}, \\
12.2,1.8)\end{array}$ & $\begin{array}{c}3.89(\mathrm{~d}, \mathrm{~d}, 12.2 \\
1.8)\end{array}$ & $\begin{array}{c}3.89(\mathrm{~d}, \mathrm{~d}, 12.2 \\
1.8)\end{array}$ & $\begin{array}{l}3.91(\mathrm{~d}, \mathrm{~d}, \\
12.5,2.0)\end{array}$ & $\begin{array}{c}3.89(\mathrm{~d}, \mathrm{~d}, 12.2 \\
1.8)\end{array}$ & $\begin{array}{l}3.89(\mathrm{~d}, \mathrm{~d}, \\
12.2,1.8)\end{array}$ \\
\hline H-2" & $7.14(\mathrm{~d}, 1.8)$ & $\begin{array}{c}7.31 \\
\left(\mathrm{~s}, \mathrm{w}_{1 / 2}=3\right)\end{array}$ & $\begin{array}{c}7.31 \\
\left(\mathrm{~s}, \mathrm{w}_{1 / 2}=3\right)\end{array}$ & $\begin{array}{c}7.15 \\
\left(\mathrm{~s}, \mathrm{w}_{1 / 2}=3\right)\end{array}$ & $\begin{array}{c}7.56 \\
\left(\mathrm{~s}, \mathrm{w}_{1 / 2}=3\right)\end{array}$ & $\begin{array}{c}7.56 \\
\left(\mathrm{~s}, \mathrm{w}_{1 / 2}=3\right)\end{array}$ \\
\hline H-5" & $7.21(\mathrm{~d}, 8.6)$ & 7.19 & 7.19 & $7.19(\mathrm{~d}, 8.6)$ & $7.17(\mathrm{~d}, 8.6)$ & $7.17(\mathrm{~d}, 8.6)$ \\
\hline H-6" & $\begin{array}{c}7.08(\mathrm{~d}, \mathrm{~d} \\
8.3,1.8)\end{array}$ & 7.19 & 7.19 & $\begin{array}{c}7.00(\mathrm{~d}, \mathrm{~d}, 8.3 \\
1.8)\end{array}$ & $\begin{array}{c}7.13(\mathrm{~d}, \mathrm{~d}, 8.6 \\
1.8)\end{array}$ & $\begin{array}{c}7.13(\mathrm{~d}, \mathrm{~d}, 8.6 \\
1.8)\end{array}$ \\
\hline H-7" & $7.60(\mathrm{~d}, 16.1)$ & $7.66(\mathrm{~d}, 16.0)$ & $7.66(d, 15.8)$ & $6.97(\mathrm{~d}, 12.8)$ & $6.97(\mathrm{~d}, 12.8)$ & $6.97(\mathrm{~d}, 12.8)$ \\
\hline H-8" & $6.40(\mathrm{~d}, 16.1)$ & $6.50(\mathrm{~d}, 16.0)$ & $6.50(\mathrm{~d}, 15.8)$ & $5.90(\mathrm{~d}, 12.8)$ & $5.93(\mathrm{~d}, 12.8)$ & $5.93(\mathrm{~d}, 12.8)$ \\
\hline $\mathrm{H}-10^{\prime \prime}$ & & $3.92(\mathrm{~s})$ & $3.92(\mathrm{~s})$ & & $3.87(\mathrm{~s})$ & $3.87(\mathrm{~s})$ \\
\hline
\end{tabular}

Multiplicity of signals: $\mathrm{s}$ - singlet; $\mathrm{d}$ - doublet; $\mathrm{t}$ - triplet; $\mathrm{m}$ - multiplet; br - broad signal. $\mathrm{w}_{1 / 2}$ : width at half-height in Hertz. ax: axial. eq: equatorial.

Table 3. ${ }^{13} \mathrm{C}-\mathrm{NMR}$ data for compounds $\mathbf{1}-\mathbf{6}$ in $\mathrm{CD}_{3} \mathrm{OD}(\delta$ in ppm, $J$ in $\mathrm{Hz}$ ).

\begin{tabular}{cccccccc}
\hline & Multiplicity & $\boldsymbol{\delta}_{\mathbf{C}}(\mathbf{1})$ & $\boldsymbol{\delta}_{\mathbf{C}}(\mathbf{2})$ & $\boldsymbol{\delta}_{\mathrm{C}}(\mathbf{3})$ & $\boldsymbol{\delta}_{\mathrm{C}}(\mathbf{4})$ & $\boldsymbol{\delta}_{\mathrm{C}}(\mathbf{5})$ & $\boldsymbol{\delta}_{\mathrm{C}}(\mathbf{6})$ \\
\hline $\mathrm{C}-1$ & $\mathrm{CH}_{2}$ & 30.1 & 30.1 & 30.1 & 30.1 & & 30.4 \\
$\mathrm{C}-2$ & $\mathrm{CH}_{2}$ & & 26.3 & 26.3 & & & 26.3 \\
$\mathrm{C}-3$ & $\mathrm{CH}$ & 69.5 & 69.4 & 69.4 & 69.5 & 69.4 & 69.4 \\
$\mathrm{C}-4$ & $\mathrm{CH}_{2}$ & & 26.3 & 30.3 & & & \\
$\mathrm{C}-5$ & $\mathrm{CH}$ & 53.1 & 53.0 & 53.1 & 52.8 & 52.9 & 53.0 \\
\hline
\end{tabular}


Table 3. Cont.

\begin{tabular}{|c|c|c|c|c|c|c|c|}
\hline & Multiplicity & $\delta_{\mathrm{C}}(\mathbf{1})$ & $\delta_{\mathrm{C}}(2)$ & $\delta_{C}(3)$ & $\delta_{C}(4)$ & $\delta_{C}(5)$ & $\delta_{C}(6)$ \\
\hline C-6 & $\mathrm{C}$ & $*$ & 206.1 & 205.6 & $*$ & $*$ & $*$ \\
\hline $\mathrm{C}-7$ & $\mathrm{CH}$ & 121.8 & 121.7 & 121.5 & 121.8 & 121.7 & 121.5 \\
\hline C-8 & $\mathrm{C}$ & $*$ & $*$ & $*$ & $*$ & $*$ & $*$ \\
\hline C-9 & $\mathrm{CH}$ & 37.8 & 37.3 & 37.4 & 37.8 & & 37.5 \\
\hline $\mathrm{C}-10$ & $\mathrm{C}$ & & 37.3 & 37.4 & & & \\
\hline $\mathrm{C} 11$ & $\mathrm{CH}_{2}$ & & 21.4 & 21.5 & & & 21.5 \\
\hline $\mathrm{C} 12$ & $\mathrm{CH}_{2}$ & 32.4 & 32.5 & 32.0 & 32.4 & 32.5 & 32.1 \\
\hline $\mathrm{C}-13$ & $\mathrm{C}$ & 49.0 & 49.0 & 48.2 & 49.0 & 49.0 & 47.4 \\
\hline C-14 & $\mathrm{C}$ & 85.6 & 85.4 & 85.4 & 85.6 & 85.6 & 85.4 \\
\hline$C-15$ & $\mathrm{CH}_{2}$ & 31.6 & 31.7 & 31.6 & 31.6 & 31.7 & 31.6 \\
\hline $\mathrm{C}-16$ & $\mathrm{CH}_{2}$ & 21.4 & 21.4 & 26.9 & 21.4 & 21.4 & 26.9 \\
\hline C-17 & $\mathrm{CH}$ & 50.5 & 50.5 & 48.6 & 50.5 & 50.5 & 48.6 \\
\hline C-18 & $\mathrm{CH}_{3}$ & 17.9 & 17.9 & 15.9 & 17.9 & 17.9 & 15.9 \\
\hline C-19 & $\mathrm{CH}_{3}$ & 24.2 & 24.2 & 24.2 & 24.2 & 24.2 & 24.2 \\
\hline $\mathrm{C}-20$ & $\mathrm{C}$ & 77.7 & 77.7 & $43.3 \mathrm{CH}$ & & 77.7 & $43.3 \mathrm{CH}$ \\
\hline $\mathrm{C}-21$ & $\mathrm{CH}_{3}$ & 20.9 & 20.8 & 13.0 & 20.9 & 20.8 & 13.0 \\
\hline $\mathrm{C}-22$ & $\mathrm{CH}$ & 78.3 & 78.3 & 75.0 & 78.3 & 78.3 & 75.0 \\
\hline $\mathrm{C}-23$ & $\mathrm{CH}_{2}$ & 27.3 & 27.3 & 25.2 & & & 25.2 \\
\hline $\mathrm{C}-24$ & $\mathrm{CH}_{2}$ & 42.3 & 42.2 & 42.2 & 42.3 & 42.2 & 42.2 \\
\hline C- 25 & $\mathrm{C}$ & 71.3 & 71.1 & 71.1 & 71.3 & 71.1 & 71.1 \\
\hline $\mathrm{C}-26$ & $\mathrm{CH}_{3}$ & 28.9 & 29.0 & 29.0 & 28.9 & 29.0 & 29.0 \\
\hline $\mathrm{C}-27$ & $\mathrm{CH}_{3}$ & 29.7 & 29.3 & 29.3 & 29.7 & 29.3 & 29.3 \\
\hline$C-1^{\prime}$ & $\mathrm{CH}$ & 103.3 & 102.1 & 102.1 & 103.3 & 102.1 & 102.1 \\
\hline $\mathrm{C}-2^{\prime}$ & $\mathrm{CH}$ & 74.6 & 74.9 & 74.9 & 74.6 & 74.9 & 74.9 \\
\hline C-3' & $\mathrm{CH}$ & 77.5 & 77.6 & 77.6 & 77.5 & 77.6 & 77.6 \\
\hline C-4' & $\mathrm{CH}$ & 71.2 & 71.29 & 71.3 & 71.2 & 71.29 & 71.3 \\
\hline C-5' & $\mathrm{CH}$ & 78.1 & 78.1 & 78.1 & 78.1 & 78.1 & 78.1 \\
\hline C-6' & $\mathrm{CH}_{2}$ & 62.3 & 62.4 & 62.2 & 62.3 & 62.4 & 62.2 \\
\hline C-1" & $\mathrm{C}$ & 131.0 & 130.4 & 130.4 & 132.1 & & 131.2 \\
\hline C-2" & $\mathrm{CH}$ & 115.9 & 112.3 & 112.3 & 117.8 & 114.9 & 114.8 \\
\hline C-3" & $\mathrm{C}$ & 148.4 & 150.7 & 150.7 & 147.8 & & 150.1 \\
\hline C-4" & $\mathrm{C}$ & 148.7 & 149.5 & 149.5 & 146.8 & 147.9 & 148.9 \\
\hline C-5" & $\mathrm{CH}$ & 117.9 & 117.1 & 117.1 & 117.6 & 117.0 & 117.0 \\
\hline C-6" & $\mathrm{CH}$ & 122.2 & 123.4 & 123.4 & 122.7 & 124.8 & 124.7 \\
\hline C-7" & $\mathrm{CH}$ & 146.0 & 145.8 & 145.8 & 143.5 & & 143.8 \\
\hline C-8" & $\mathrm{CH}$ & 117.3 & 117.5 & 117.5 & 119.9 & 119.4 & 119.5 \\
\hline C-9" & $\mathrm{C}$ & 168.1 & 168.0 & 168.0 & 162.2 & & 167.5 \\
\hline C-10" & $\mathrm{CH}_{3}$ & & 56.7 & 56.7 & & 56.3 & 56.7 \\
\hline
\end{tabular}

* Signal not detected (too low concentration of the sample).

\section{Conclusions}

A chemical investigation of Microsorum membranifolium fronds was carried out within the framework of a thorough investigation of French Polynesia flora. This study showed that the fronds contained a new phytoecdysteroid, E-2-deoxy-20-hydroxyecdysone 3-[4-(1- $\beta$-D-glucopyranosyl)]caffeate (1), together with the known compounds E-2-deoxy-20-hydroxyecdysone 3-[4-(1- $\beta$-Dglucopyranosyl)]-ferulate (2) and E-2-deoxyecdysone 3-[4-(1- $\beta$-D-glucopyranosyl)]-ferulate (3). In the 
same way, we identified their respective cis isomers 4-6 for the first time. Their structures were established on the basis of spectroscopic evidence. These results will lead us to find further novel secondary metabolites in Polynesian medicinal ferns.

\section{Acknowledgments}

Critical reading of the manuscript by Laurence Dinan is deeply acknowledged.

\section{References}

1. Pétard, P. Plantes utiles de Polynésie Raau Tahiti, 2nd ed.; Haere po no Tahiti: Papeete, French Polynesia, 1986; pp. 77-78.

2. Grepin, F.; Grepin, M. La Médecine Tahitienne Traditionnelle, 1st ed.; Les éditions du pacifique: Tahiti, French Polynesia, 1984; pp. 1-151.

3. Cambie, R.C.; Ash, J. Fijian Medicinal Plants, 1st ed.; CSIRO: East Melbourne, Australia, 1994; pp. 1-365.

4. Ho, R.; Teai, T.; Loquet, D.; Bianchini, J.P.; Girault, J.P.; Lafont, R.; Raharivelomanana, P. Phytoecdysteroids in the genus Microsorum (Polypodiaceae) of French Polynesian. Nat. Prod. Commun. 2007, 8, 803-806.

5. Ho, R.; Girault, J.P.; Cousteau, P.Y.; Bianchini, J.P.; Raharivelomanana, P.; Lafont, R. Isolation of a new class of ecdysteroid conjugates (Glucosyl-ferulates) using a combination of liquid chromatographic methods. J. Chromatogr. Sci. 2008, 46, 102-110.

6. Lafont, R.; Harmatha, J.; Marion-Poll, F.; Dinan, L.; Wilson, I.D. Ecdybase-A free ecdysteroid database, 2002 continuously updated. Available online: http://ecdybase.org (accessed on 19 August 2012).

7. Girault, J.P.; Bathori, M.; Varga, E.; Szendrai, K.; Lafont, R. Isolation and identification of new ecdysteroids from Caryophyllaceae. J. Nat. Prod. 1990, 53, 279-293.

8. Maria, A; Girault, J.P.; Saatov, Z.; Harmatha, J.; Dinan, L.N.; Lafont, R. Ecdysteroid glycosides: Chromatographic properties and biological activity. J. Chromatogr. Sci. 2005, 43, 149-157.

9. Kahnt, G. Trans-cis-equilibrium of hydroxycinnamic acids during irradiation of aqueous solutions at different $\mathrm{pH}$. Phytochemistry 1967, 6, 755-758.

10. Locher, R.; Martin, H.V.; Grison, R.; Pilet, P.E. Cell wall-bound trans- and cis-ferulic acids in growing maize roots. Physiol. Plant. 1994, 90, 734-738.

11. Girault, J.P. Determination of ecdysteroid structure by 1D and 2D NMR. Russ. J. Plant Physiol. 1998, 45, 306-309.

Sample Availability: Samples of E-2-deoxy-20-hydroxyecdysone 3-[4-(1- $\beta$-D-glucopyranosyl)]caffeate, $E$-2-deoxy-20-hydroxyecdysone 3-[4-(1- $\beta$-D-glucopyranosyl)]-ferulate, $E$-2-deoxyecdysone 3 -[4-(1- $\beta$-D-glucopyranosyl)]-ferulate are available from the authors.

(C) 2012 by the authors; licensee MDPI, Basel, Switzerland. This article is an open access article distributed under the terms and conditions of the Creative Commons Attribution license (http://creativecommons.org/licenses/by/3.0/). 